\title{
O ENSINO DE INGLÊS NO ENSINO MÉDIO: PERSPECTIVAS EDUCOMUNICATIVAS
}

\author{
Luciana Souza de Oliveira Costa ${ }^{1}$ \\ Vanice dos Santos ${ }^{2}$
}

\begin{abstract}
Resumo
Esta pesquisa objetiva compreender a educomunicação como potencializadora do processo de aprendizagem da Língua Inglesa por alunos do Ensino Médio. Remetemos a pesquisa à Educomunicação, considerando as profícuas contribuições que a recente área pode oferecer, promovendo mais significado na construção do conhecimento comunicativo da língua, cujos conteúdos e metodologias atuais, por vezes, parecem não fazer sentido para os discentes e pouco têm contribuído para o processo de aprendizagem. Considera-se que mudanças no processo de construção de conhecimento no ambiente escolar precisam acontecer, estabelecendo ecossistemas educomunicativos em que os sujeitos exerçam com autonomia a elaboração de sentidos de acordo com suas realidades e identidades culturais, podendo agregá-los de forma a construírem juntos e de forma dinâmica os novos saberes.
\end{abstract}

Palavras-chave: Educomunicação. Ensino Médio. Língua Inglesa.

\section{English Language teaching in High School: educommunicative perspectives}

\begin{abstract}
This search aims to understand the educommunication as a potentiator of the process of learning English Language by High School students. We refer the research to Educommunication, considering the profitable contributions that the recent area can offer, promoting more meaning in the construction of the language's communicative knowledge, whose current contents and methodologies, sometimes, do not seem to make sense to the students and almost haven't contributed for learning process. We consider that changes in the process of knowledge construction in the school environment need to happen, establishing educommunicative ecosystems in which subjects can be able to exercise with autonomy the elaboration of meanings according to their realities and cultural identities, being capable to aggregate them to construct the new knowledge together dynamically.
\end{abstract}

Keywords: Educommunication. High School. English Language.

\section{Iniciando a Conversa}

${ }^{1}$ Mestranda em Educação na Universidade do Planalto Catarinense (UNIPLAC), Lages, SC, Brasil. Pós-graduada em Língua Inglesa -Professora na Educação Básica da Rede Municipal de Ensino de Lages. Professora na Educação Básica da Rede Estadual de Ensino de Santa Catarina. E-mail: lu.sou.oli@gmail.com

2 Docente pesquisadora no Programa de Pós-Graduação em Educação da Universidade do Planalto Catarinense (UNIPLAC), Lages, SC, Brasil. Doutora em Educação pela Universidade Federal do Rio Grande dos Sul (UFRGS), Mestre e Licenciada em Filosofia pela Universidade do Vale do Rio dos Sinos (UNISINOS). Líder do Grupo de Pesquisa NESEF - Regional Planalto Catarinense. E-mail: vanicedossantos@gmail.com.

Criar Educação, Criciúma, v. 8, nº1, jan/jul 2019.- PPGE - UNESC 
Comunicar-se é um ato inerente e necessário ao ser humano desde o início de sua existência. Dentre as inúmeras maneiras de comunicação, a linguagem se difundiu ao longo dos anos, sendo usada de forma oral ou escrita, variando seus signos de acordo com a cultura e a localização geográfica das comunidades que a davam sentido e vida. Por meio da comunicação a humanidade passou a construir conhecimentos, compartilhar experiências e deixá-los como legado às novas gerações por meio de signos linguísticos socialmente determinados.

Assim, cada comunidade comunica-se, institui normas de convivência, se relaciona por meio de inúmeros signos, dentre eles sua língua local, materna. No entanto, as relações não se limitam as suas comunidades, pois, cada vez mais, as pessoas viajam e interagem, física ou virtualmente, por diversas partes do mundo, o que sinaliza a necessidade de saber comunicar-se em outras línguas, além da sua.

Ao pensar sobre o aprendizado de línguas, pressupõe-se que o desenvolvimento dos estudantes perpassa mais que o desenvolvimento de competências linguísticas e comunicativas. Pois, para internalizar as singularidades de cada língua, supões-se que o sujeito compreenda as relações sociais, políticas, educacionais e culturais do contexto de sua utilização. Há que se desenvolver uma concepção e uma consciência críticas acerca desse ambiente comunicativo como um todo.

Vivemos em um período de constantes transformações, cujos reflexos se apresentam, positiva ou negativamente, nos mais variados segmentos, independentemente de nossa vontade. As pessoas mudam seus modos de viver, de aprender, de trabalhar, suas relações interpessoais, seus conhecimentos e crenças, enfim, mudam e são mudados.

Por estas, entre outras razões, percebemos conflitos entre o que a escola oferece às recentes gerações e as suas demandas, considerando que fazem parte dessa expressiva transformação. Os jovens anseiam por expressar sua voz, serem ouvidos e poderem se exprimir da maneira como se sentirem confortáveis, buscando variáveis que os encorajem a enfrentar os desafios a que se proponham superar.

Destarte, a partir da experiência em ambientes digitais, os jovens, por vezes, sentem-se encorajados a superar medos e expor angústias, com liberdade de fazer 
produções autorais em infinitos contextos e linguagens. Atualmente, nossos alunos clamam por reconhecimento enquanto sujeitos ativos de um processo em que o conhecimento se transforma à medida das necessidades de uma sociedade em movimento e inovação constantes. O processo de construção de conhecimento precisa de renovação, pois nada é definitivo e muito é criado e reinventado constantemente.

Considerando todas as premissas apontadas anteriormente, a intenção, neste artigo, é a de encontrar novas possibilidades para as práticas escolares, especialmente para a disciplina de Língua Inglesa no Ensino Médio. Isto porque seus conteúdos e metodologias propostos têm sido subaproveitados por uma parcela significativa de estudantes, os quais necessitam encontrar sentido, descobrir o significado do que necessitam aprender, considerando o que as diretrizes educacionais propõem.

Ao analisar os paradigmas inerentes ao campo da Educomunicação, vislumbramos uma perspectiva de práticas educomunicativas que possam vir a contribuir com o processo de aprendizagem de Língua Inglesa no Ensino Médio. A partir das reformas propostas por documentos, como os Parâmetros Curriculares Nacionais e a Base Nacional Comum Curricular, para essa etapa escolar, mais que nunca, a contextualização de competências linguístico-comunicativas necessita estar agregada à objetivos sociais e culturais. Estes se comprometem com o desenvolvimento de estudantes ansiosos por protagonizarem com autonomia a construção de seus conhecimentos e que estejam aptos a exercerem suas cidadanias.

Esta pesquisa tem caráter qualitativo exploratório, com revisão bibliográfica que respalda o objetivo proposto: compreender como as práticas educomunicativas podem contribuir para o processo de ensino e aprendizagem da Língua Inglesa no Ensino Médio. Em andamento, este estudo compreende parte da trajetória de investigação de uma dissertação para o Mestrado Acadêmico em Educação da Uniplac, em Lages, cuja pesquisa encontra-se em fase inicial de análise de dados coletados por meio de entrevistas com professores e questionários com estudantes de inglês no Ensino Médio. 


\section{As linguagens na reforma do Ensino Médio - Língua Inglesa em foco}

Reformas e mudanças têm marcado o cenário educacional, principalmente relacionado ao Ensino Médio, conduzindo o estudo das políticas públicas nacionais, bem como têm sido tema de discussão entre diversos segmentos educacionais acerca dos rumos, objetos e propostas que destinarão a educação brasileira. $O$ empenho é para que as necessidades educacionais da sociedade sejam contempladas em suas integralidades, formando estudantes com conhecimentos e saberes científicos. Isto é, essencialmente, para que cada um se torne o cidadão que exerça criticamente e reflexivamente sua cidadania, emancipados com a contribuição de práticas pedagógicas que incentivem o desenvolvimento do conhecimento associado à autonomia, à participação ativa e à consciência crítica.

Segundo as Diretrizes Nacionais para a Educação Básica, no que se refere ao Ensino Médio,

Tendo em vista que a função precípua da educação, de um modo geral, e do Ensino Médio - última etapa da Educação Básica - em particular, vai além da formação profissional, e atinge a construção da cidadania, é preciso oferecer aos nossos jovens novas perspectivas culturais para que possam expandir seus horizontes e dotá-los de autonomia intelectual, assegurando-Ihes 0 acesso ao conhecimento historicamente acumulado e a produção coletiva de novos conhecimentos, sem perder de vista que a educação também é, em grande medida, uma chave para o exercício dos demais direitos sociais (BRASIL, 2013, p. 145).

Compreendemos, assim, que, embora com preocupações tangentes à formação de profissionais, a nível médio e superior, para suprir as demandas atuais do cenário brasileiro, há, também, um esforço, ou ao menos reconhecimento, de que a formação desses estudantes perpasse questões sociais que os prepare na integralidade.

O desenvolvimento das linguagens, em ambiente escolar, mais que preparar mecanicamente os estudantes para os processos de leitura e escrita, tem papel fundamental para o exercício de interpretação de texto, contexto e realidade como um todo. Essas fornecem meios para que a o processo de aprendizagem nas mais variadas disciplinas escolares se concretizem. A Língua Estrangeira, em meio a inúmeras discussões ao longo de décadas, é parte do currículo escolar, sendo a 
Língua Inglesa a mais recorrente nesse cenário. Partindo de tais constatações, reconhecemos nela, enquanto componente curricular, a potencialidade de conhecimento e reconhecimento de culturas, de formação cidadã consciente e aberto à diversidade, pautada no respeito mútuo. Vale ressaltar, também, que textos acadêmicos denominam, ao invés de Língua Estrangeira, Língua Adicional, - como é o caso do artigo "Ensinar e aprender língua estrangeira/adicional na escola: a relação entre perspectivas críticas e uma experiência prática localizada" - uma vez que, no contexto de intercâmbio multicultural que vivenciamos, a hibridização entre nativos e estrangeiros é cada vez mais constante. Além disso, o conhecimento de uma nova língua contempla uma maior amplitude de conhecimento para os estudantes.

Trazemos as Orientações Curriculares para o Ensino Médio (OCPEM) para reiterar os objetivos que compõem a disciplina de Língua Inglesa na educação formal escolar que:

[...] visa a ensinar um idioma estrangeiro e, ao mesmo tempo, cumprir outros compromissos com os educandos, como, por exemplo, contribuir para a formação de indivíduos como parte de suas preocupações educacionais [...] Quando falamos sobre o aspecto educacional do ensino de Línguas Estrangeiras, referimo-nos, por exemplo, à compreensão do conceito de cidadania, enfatizando-o (BRASIL, 2008, p. 91).

Cidadania, ou ser cidadão, para este documento, envolve a concepção do aluno acerca de sua dimensão de posição ou lugar no contexto social. Segundo estas Orientações, a aprendizagem de línguas estrangeiras tem valores educacionais que transcendem a capacidade comunicativa da língua.

Em relação a essa contraposição de concepções de aprendizagem, entre o ensino comunicativo da língua estrangeira e o letramento crítico social nas aulas de Língua Estrangeira, apontadas nas OCPEM, Mattos e Valério (2010, p. 140) consideram que uma não é suprimida em relação à outra, mas complementares, pois:

Apesar de díspares em relação às tradições teóricas das quais são oriundas, as duas abordagens compartilham alguns de seus preceitos e conceitos mais básicos. Dentre eles, destacaremos aqui o protagonismo do aprendiz e a centralidade da heterogeneidade. Focalizaremos também alguns princípios e conceitos que, servindo de contato entre as duas abordagens, constituem-se em excelentes veios para transposição didática,

Criar Educação, Criciúma, v. 8, nº1, jan/jul 2019.- PPGE - UNESC 

assim como algumas práticas pedagógicas disseminadas por abordagens voltadas para o desenvolvimento da consciência linguística.

Destacamos, nesta perspectiva apontada pelas autoras, a preconização do protagonismo dos jovens aprendizes.Tal protagonismo pressupõe como princípio norteador o perfil de heterogeneidade das gerações advindas no século XXI. Os jovens estudantes deste contexto de transformações em que vivemos na contemporaneidade se apresentam como sujeitos ativos e perquiridores de seus próprios caminhos e respostas, que não assentem em calar-se ante suas dúvidas, que buscam liberdade e resistem às imposições, por acreditarem que aquilo que Ihes é mediado como conhecimento em potencial, necessita apresentar-se com sentido significativo para que seja aprendido.

\section{A práxis educomunicativa para a aproximação da juventude com o contexto escolar}

O relativamente recente campo da educomunicação, cujas pesquisas passaram a se concretizar com credibilidade, na América Latina e especialmente no Brasil, há cerca de três décadas, é um paradigma em construção que se apresenta como potencialidade às práticas educacionais num contexto interdisciplinar. Compreendido pela intersecção entre Educação e Comunicação, este campo oferece uma nova maneira de pensar e executar a educação, partindo da premissa de que:

\footnotetext{
Se existem novas formas de viver, sentir e pensar, é preciso que se pense também nas novas formas de aprender e, portanto, nas novas formas de ensinar, nas novas expectativas e novas demandas, não só dos sujeitosalunos, mas também dos sujeitos-professores, já que todos estão inseridos (em maior ou em menor grau) nesta contemporaneidade repleta de tecnologias e mídias (SARTORI et al., 2014, p.68).
}

Reconhecemos que os conceitos e preceitos educomunicativos independem das tecnologias e mídias que possam ser associadas as suas práticas. O referencial teórico, de origem South to South, é firmado por relevantes nomes latino-americanos de estudo em educação e comunicação, tais como: Paulo Freire, Mário Kaplún, 
Jesús Martín-Barbero, Guillermo Orozco Gómez e Ismar de Oliveira Soares. Assim, o conceito de Educomunicação, segundo a Associação Brasileira de Pesquisadores e Profissionais em Educomunicação (ABPEducom), passa a ser entendido como:

\begin{abstract}
um paradigma orientador de práticas sócio-educativo-comunicacionais que têm como meta a criação e fortalecimento de ecossistemas comunicativos abertos e democráticos nos espaços educativos, mediante a gestão compartilhada e solidária dos recursos da comunicação, suas linguagens e tecnologias, levando ao fortalecimento do protagonismo dos sujeitos sociais e ao consequente exercício prático do direito universal à expressão.
\end{abstract}

Percebemos, portanto, que a Educomunicação é um campo interdisciplinar pautado no diálogo, na cidadania, na construção coletiva de conhecimento criativo e crítico, que pode, ou não, valer-se de mídias e tecnologias digitais para a sua sustentação.

Contudo, a difusão tecnológica é uma constante inquestionável, embora não distribuída homogeneamente entre a sociedade, no século XXI, fazendo parte, de alguma maneira, do cotidiano de inúmeros cidadãos. É importante ressaltar que as desigualdades de acesso às tecnologias perpassam por antigas questões relacionadas à desigualdade social, em que o acesso à elas demanda poder aquisitivo. "O uso das mídias digitais parece de fato favorecer o surgimento de novas posições e papéis no interior das redes sociais, contribuindo não só com a exacerbação das antigas desigualdades, mas também com a criação de novas formas de iniquidade." (PISCHETOLA, 2016, p. 34).

Destarte, consideramos, em nossos estudos, a associação de educomunicação aos meios tecnológicos e midiáticos digitais presentes no contexto contemporâneo da sociedade, como possibilidade de oportunizar aos estudantes o acesso à perspectivas educacionais criativas, autônomas e emancipadoras que os permitam, por práticas coletivas e dialógicas, a leitura crítica da realidade.

Nesta perspectiva, professores e estudantes passam por uma certa crise de identidade e posição frente às inúmeras e bruscas mudanças que o universo digital tem induzido no cenário educacional.

Em outras palavras, discute-se sobre os atuais e os vindouros paradigmas da educação em seu confronto/associação com o mundo da informação e sobre o papel do professor/instrutor nesta revolução tecnológica. Ou eles conseguem decifrar o que está ocorrendo e se preparam para assumir

Criar Educação, Criciúma, v. 8, nº1, jan/jul 2019.- PPGE - UNESC 
papel protagônico no processo, ou serão substituídos por que se disponha a servir o sistema que está sendo implantado. (SOARES, 2011a, p.13).

Segundo Soares (2011a), muitos estudiosos apontam que, mais relevante que as tecnologias difundidas, o modelo de comunicação que se desenvolve, a partir delas, é a grande chave para a superação de paradigmas na contemporaneidade. $O$ alcance de êxitos no ato de educar dependerá das ações comunicativas que se estabeleçam nesse processo, uma vez que, para que o diálogo entre educação e comunicação se estabeleça, de acordo com Soares (2011b, p. 17),

[...] partimos de dois axiomas: o primeiro afirma que a educação só é possível enquanto "ação comunicativa", uma vez que a comunicação configura-se, por si mesma, como um fenômeno presente em todos os modos de formação do ser humano [...]. O segundo axioma afirma que toda comunicação - enquanto produção simbólica e intercâmbio/transmissão de sentidos - é, em si, uma "ação educativa".

Isto se aplica a todo o contexto educacional, mas, neste momento, ainda destacamos esta relevância para o movimento de aprendizagem de línguas, sejam elas a materna ou as estrangeiras/adicionais.

Ao encontro deste pensamento, buscamos a Educomunicação que, fundamentada em ecossistemas comunicativos, preconiza a construção coletiva de conhecimentos, alicerçada pelo respeito mútuo, por meio de compartilhamento de ideias e concepções, numa relação horizontal dialógica. Neste sentido, dando suporte às assertivas acerca de tecnologias e ecossistemas comunicativos, MartínBarbero (2011, p. 125) enfatiza que:

\begin{abstract}
A primeira manifestação e materialização do ecossistema comunicativo é a relação com as novas tecnologias - desde o cartão que substitui ou dá acesso ao dinheiro, até as grandes avenidas da Internet -, com sensibilidades novas, claramente visíveis entre os mais jovens. Eles têm maior empatia cognitiva e expressiva com as tecnologias e com os novos modos de perceber o espaço e o tempo, a velocidade e a lentidão, o próximo e o distante. Trata-se de uma experiência cultural nova, ou, como chamou Walter Benjamin, um sensorium novo. Novos modos de perceber e de sentir; uma nova sensibilidade que, em muitos aspectos, se choca e rompe com o sensorium dos alunos.
\end{abstract}

$\mathrm{Na}$ concepção de ecossistema comunicativo, o estudante protagoniza o seu processo de aprendizagem - com liberdade de expressar seu pensamento - e o 
professor passa a mediar esse movimento de desenvolvimento cognitivo na coletividade. Esta proposta educomunicacional instiga o desenvolvimento de autonomia, autoconfiança, autoria, cooperação, interação, respeito, cidadania, gestão participativa, emancipação e participação social, pelas quais o estudante percebe-se como o centro do próprio processo de aprendizagem. Considera-se, assim, que práticas pautadas na educomunicação permitem aos jovens a significação com sentido, partindo para uma reflexão crítica acerca do conhecimento em construção, pela qual formar-se-á integralmente para o exercício de seu papel social de cidadania.

Nesse viés de liberdade, cidadania e relações dialógicas, remetemos nosso estudo ao pensador brasileiro que é a base pelo paradigma educomunicacional. Paulo Freire elucidou com perspicácia e parcimônia a educação voltada para a liberdade, enfatizando a relação de horizontalidade entre os sujeitos envolvidos no processo educativo, uma vez que todos têm o que ensinar e o que aprender:

[...] educar e educar-se, na prática da liberdade, é tarefa daqueles que sabem que pouco sabem - por isto sabem que sabem algo e podem assim chegar a saber mais - em diálogo com aquêles que, quase sempre, pensam que nada sabem, para que êstes, transformando seu pensar que nada sabem em saber que pouco sabem, possam igualmente saber mais. (FREIRE, 1983, p. 15)

Essa relação de educar, educar-se e ser educado perpassa, também, as concepções de dialogicidade defendidas pelo mesmo autor, pelas quais, os sujeitos vivenciam o diálogo e, desta forma, se envolvem em um movimento constante de transformação da realidade e de humanização. Por meio do encontro entre os envolvidos, pautados na amorosidade e no respeito, os homens pronunciam o mundo e por ele são mediatizados, buscando meios conciliadores.

Ser dialógico é não invadir, é não manipular, é não sloganizar. [...] Esta é a razão pela qual, sendo o diálogo o conteúdo da forma de ser própria à existência humana, está excluído de tôda relação na qual alguns homens sejam transformados em "sêres para outro" por homens que são falsos "sêres para si". É que o diálogo não pode travar-se numa relação antagônica. [...] Não há nem pode haver invasão cultural dialógica; não já manipulação nem conquista dialógicas: êstes são têrmos que se excluem. (FREIRE, 1983, p.28). 
Conexões passam a se estabelecer como consequência de iniciativas que se direcionam ao desenvolvimento de competências educomunicativas. Uma competência vem atrelada a outra, uma vez que, ao invocar os ecossistemas comunicativos, trazemos junto a ele outras características inerentes ao conceito educomunicativo, tais como o diálogo, a autonomia, a produção autoral e o protagonismo. Todos estes paradigmas sinalizam 0 desenvolvimento de aprendizagens mediadas por movimentos de colaboração, bem como a construção coletiva de conhecimento.

A escola vem perdendo o cunho de ser a principal instituição educativa com legitimidade para, como em séculos anteriores, transmitir conhecimento e formar cidadãos. Outros espaços e meios têm difundido o acesso à informação e reinventado as formas de interação e construção de conhecimento. Segundo Orozco Gómez (1999, p. 68), para que as instituições escolares se adéquem à nova realidade,

A escola, em uma nova perspectiva, já não seria o centro depositário do conhecimento e do saber, mas teria que se transformar em um centro de reconhecimento e articulação de múltiplos conhecimentos e informações que circulam usualmente, para orientar os educandos sobre a forma de como associá-los para seus fins de aprendizado. [...] Portanto, o que ficou dito permite sustentar que, em uma escola do futuro, a diferenciação entre o que é uma eduçação formal e outra que não o é, não terá cabimento. (OROZCO GOMÉZ, 1999, p. 68)

Isto porque, segundo Pischetola (2016), a estrutura midiática das tecnologias digitais mudaram as características entre espectador e participante. Pois, por meio das mídias, é possível desenvolver, de maneira autoral, as construções, ou colaborações, de inúmeras formas de conhecimento e comunicação, por meio de produções significativas, ora de forma pessoal, ora colaborativa.

\section{Considerações Finais}

Há uma vultuosa convergência de objetivos, propostas e expectativas relacionadas às diretrizes, orientações e demais documentos que regem o Ensino de Língua Estrangeira - Inglês no Ensino Médio com as proposições, aqui evidenciadas, acerca das concepções de Educomunicação.

Criar Educação, Criciúma, v. 8, nº1, jan/jul 2019.- PPGE - UNESC 
Em relação à Língua Inglesa, embora sejam claros e evidentes os estudos e direcionamentos proferidos como bússola às práticas pedagógicas, percebemos que ainda há uma longa distância a ser percorrida no exercício escolar, em direção ao norte - ou ao sul - apontado pelos regimentos educacionais.

Além disso, temos vivenciado desafios cada vez maiores quanto ao envolvimento, ou a falta dele, por parte dos estudantes, em relação ao contexto escolar como um todo. As tradicionais práticas e metodologias, que vigoram há séculos, já não mais atingem os objetivos e competências educacionais necessários na contemporaneidade.

Nesse sentido, reconhecemos na educomunicação, associada às possibilidades das mídias e tecnologias digitais, uma potencialidade propulsora de práticas que se condicionem à realidade dos estudantes e os promovam à protagonistas de seus processos de aprendizagem.

\section{Referências}

ABPEducom. 0 que é educomunicação? Disponível em: <http://www.abpeducom.org.br/>. Acesso em: 09 out. 2017.

BRASIL. Ministério da Educação, Secretaria de Educação Básica. Orientações Curriculares para o Ensino Médio: Linguagens, códigos e suas tecnologias. v. 1., Brasília: 2008.

BRASIL. Ministério da Educação. Diretrizes Curriculares Nacionais Gerais da Educação Básica. Brasília: MEC, SEB, DICEI, 2013.

FREIRE, P. Extensão ou comunicação? Tradução de Rosisca Darcy de Oliveira. 8. ed. Rio de Janeiro: Paz e Terra, 1983.

FREIRE, Paulo. Pedagogia do oprimido. 17. ed. Rio de Janeiro: Paz e Terra, 1987.

MARTÍN-BARBERO, Jesús. Desafios culturais: da comunicação à educomunicação. In: CITELLI, Adilson; COSTA, Maria Cristina Castilho (Orgs.). Educomunicação: Construindo uma nova área de conhecimento. 2. ed. São Paulo: Paulinas, 2011, p. 121-134.

MATTOS, Andréa Machado de Almeida; VALÉRIO, Kátia Modesto. Letramento crítico e ensino comunicativo: lacunas e interseções. RBLA, Belo Horizonte, v. 10, n. 1, p. 135-158, 2010. Disponível em: < www.scielo.br/pdf/rbla/v10n1/08.pdf>. Acesso em:23. jun. 2017.

OROZCO GÓMEZ, Guilhermo. Comunicação, educação e novas tecnologias: tríade do século XXI. Artigo Internacional. Palestra realizada na abertura do V Simpósio 
de Pesquisa em Comunicação da região Centro-Oeste, Goiânia, Brasil. Universidade Federal de Goiás. Maio, 1999.

PISCHETOLA, Magda. Inclusão digital e educação: a nova cultura da sala de aula. Petrópolis: Vozes; Rio de Janeiro: Editora PUC/Rio, 2016.

SARTORI, Ademilde Silveira et al. Desenho animado, blogs e youtube: elementos para pensar práticas pedagógicas educomunicativas. In: SARTORI, Ademilde Silveira. Educomunicação e a criação de ecossistemas comunicativos. Florianóplis: Dioesc, 2014, p. 67-86.

SOARES, Ismar de Oliveira. Educomunicação: um campo de mediações. In: CITELLI, Adilson Odair; COSTA, Maria Cristina Castilho. Educomunicação: construindo uma nova área de conhecimento. São Paulo: Paulinas, 2011, p. 13-29.

SOARES, Ismar de Oliveira. Educomunicação: o conceito, o profissional, a aplicação: contribuições para a reforma do Ensino Médio. São Paulo: Paulinas, 2011b.

Recebido em dezembro 2018

Aprovado em março 2019 